\title{
Preparation and characterization of 6-mercaptopurine-coated magnetite nanoparticles as a drug delivery system
}

This article was published in the following Dove Press journal:

Drug Design, Development and Therapy

24 September 2013

Number of times this article has been viewed

\section{Dena Dorniani'}

Mohd Zobir bin Hussein'

Aminu Umar Kura ${ }^{2}$

Sharida Fakurazi ${ }^{2}$

Abdul Halim Shaari ${ }^{3}$

Zalinah Ahmad ${ }^{4}$

'Materials Synthesis and

Characterization Laboratory, Institute

of Advanced Technology, ${ }^{2}$ Vaccines

and Immunotherapeutics Laboratory,

${ }^{3}$ Physics Department, Faculty of Science, ${ }^{4}$ Chemical Pathology Unit,

Department of Pathology, Faculty

of Medicine and Health Sciences,

Universiti Putra Malaysia, Selangor,

Malaysia
Correspondence: Mohd Zobir bin Hussein Materials Synthesis and Characterization Laboratory, Institute of Advanced

Technology, Universiti Putra Malaysia,

43400 Serdang, Selangor, Malaysia

Tel +60389468092

Fax +60389438470

Email mzobir@upm.edu.my
Background: Iron oxide nanoparticles are of considerable interest because of their use in magnetic recording tape, ferrofluid, magnetic resonance imaging, drug delivery, and treatment of cancer. The specific morphology of nanoparticles confers an ability to load, carry, and release different types of drugs.

Methods and results: We synthesized superparamagnetic nanoparticles containing pure iron oxide with a cubic inverse spinal structure. Fourier transform infrared spectra confirmed that these $\mathrm{Fe}_{3} \mathrm{O}_{4}$ nanoparticles could be successfully coated with active drug, and thermogravimetric and differential thermogravimetric analyses showed that the thermal stability of iron oxide nanoparticles coated with chitosan and 6-mercaptopurine (FCMP) was markedly enhanced. The synthesized $\mathrm{Fe}_{3} \mathrm{O}_{4}$ nanoparticles and the FCMP nanocomposite were generally spherical, with an average diameter of $9 \mathrm{~nm}$ and $19 \mathrm{~nm}$, respectively. The release of 6-mercaptopurine from the FCMP nanocomposite was found to be sustained and governed by pseudo-second order kinetics. In order to improve drug loading and release behavior, we prepared a novel nanocomposite (FCMP-D), ie, $\mathrm{Fe}_{3} \mathrm{O}_{4}$ nanoparticles containing the same amounts of chitosan and 6-mercaptopurine but using a different solvent for the drug. The results for FCMP-D did not demonstrate "burst release" and the maximum percentage release of 6-mercaptopurine from the FCMP-D nanocomposite reached about $97.7 \%$ and 55.4\% within approximately 2,500 and 6,300 minutes when exposed to $\mathrm{pH} 4.8$ and $\mathrm{pH} 7.4$ solutions, respectively. By MTT assay, the FCMP nanocomposite was shown not to be toxic to a normal mouse fibroblast cell line.

Conclusion: Iron oxide coated with chitosan containing 6-mercaptopurine prepared using a coprecipitation method has the potential to be used as a controlled-release formulation. These nanoparticles may serve as an alternative drug delivery system for the treatment of cancer, with the added advantage of sparing healthy surrounding cells and tissue.

Keywords: superparamagnetic nanoparticles, 6-mercaptopurine, controlled release, cytotoxicity, drug delivery

\section{Introduction}

Nanoparticles, with their well-controlled shapes, sizes, high surface to volume ratio, and magnetic properties ${ }^{1}$ are now widely used as drug delivery systems for the treatment of a range of systemic, oral, pulmonary, ${ }^{2}$ and kidney diseases. Magnetite nanoparticles, in particular iron oxide nanoparticles, are inorganic materials that can be coated with various polymers and/or loaded with therapeutic agents embedded in polymeric matrices. ${ }^{3}$ They have been extensively researched for drug delivery due to their tailor-made properties, strong magnetic response, and ease of preparation. ${ }^{4}$

To increase the effect of nanoparticles in biological systems, a variety of polymers, including dextran, poly(ethylene glycol), albumin, poly(ethylene oxide), aspartic acid, 
and chitosan, have been used in the coating process, enabling drug release by controlling diffusion and/or erosion of the core across the polymeric membrane or matrix. Solubility and diffusivity of the drug in the polymer membrane is an important factor in drug release. ${ }^{5}$ Magnetic nanoparticles can be used to label specific molecules, structures, and micro-organisms, and techniques have been developed by which a magnetic field can be generated by magnetically labeled targets ${ }^{6}$ and can be detected directly using a sensitive magnetometer.

Magnetic nanoparticles consist of a magnetic core and a protective coating with surface functionality, such that active biomolecules attached to the surface of these nanoparticles can be released. Previous research indicates that some nanoparticles binding antitumor agents have prolonged drug retention times in tumor tissue and slow tumor growth. ${ }^{7}$

Chitosan is a natural linear polysaccharide polymer composed of glucosamine and $\mathrm{N}$-acetylglucosamine residues derived from alkaline deacetylation of chitin. It is a popular polymer because of its favorable biological properties, which include biodegradability, biocompatibility, low toxicity, anticarcinogenicity, fungistatic, hemostatic, anticholesterolemic, and bacteriostatic activity ${ }^{8}$, its low molecular weight, and ability to adsorb proteins, peptides and genes. ${ }^{9-12}$ Chitosan can also be used in the oral delivery of poorly absorbable drugs to improve the absorption characteristics of these drugs.

Purine derivatives, such as 6-mercaptoguanine and 6-mercaptopurine, are the focus of intense interest because of their antitumor properties, particularly against leukemia, ${ }^{13-15}$ and their potent acid-base properties, which offer a variety of metallic bonding sites. ${ }^{15,16}$ Metal complexes of these bases appear to have more anticancer activity than the free ligands. ${ }^{2,17}$

Recently, 6-mercaptopurine has attracted much attention as an antineoplastic agent because of good coordination properties arising from its nitrogen and sulfur donor sites, which can be bonded at N-1, N-3, N-7, and N-9. In addition, 6-mercaptopurine has chemotherapeutic activity. It is believed that the activity of 6-mercaptopurine in cancer cells is due to its ability to transform the nitrogen donor sites into the respective ribosides. ${ }^{2}$

This paper describes the synthesis of a nanocomposite comprising iron oxide nanoparticles coated with chitosan and 6-mercaptopurine (FCMP), optimization of their release behavior by preparing a new nanocomposite (FCMP-D) containing the same amounts of chitosan and FCMP but using a different solvent for delivery, and the effects on viability in two cell lines, ie, normal mouse fibroblasts (3T3) and leukemia cells (WEHI-3) when exposed to these compounds.

\section{Materials and methods Materials}

All the materials used in this study were of analytical grade, with no further purification required. Iron (II) chloride tetrahydrate $\left(\mathrm{FeCl}_{2} \cdot 4 \mathrm{H}_{2} \mathrm{O} \geq 99 \%\right)$ and iron (III) chloride hexahydrate $\left(\mathrm{FeCl}_{3} \cdot 6 \mathrm{H}_{2} \mathrm{O}, 99 \%\right)$ were purchased from Merck KGaA (Darmstadt, Germany). Low molecular weight chitosan with a degree of deacetylation $(75 \%-85 \%)$ was sourced as a raw material from Sigma-Aldrich (St Louis, MO, USA). 6-Mercaptopurine monohydrate (99.5\%) was supplied by Acros Organics (Fair Lawn, NJ, USA). Absolute ethanol solution $(\geq 99.5 \%)$ was purchased from Sigma Chemicals (St Louis, MO, USA) and used as a solvent for 6-mercaptopurine. Aqueous acetic acid solution (99.8\%) was used as a solvent for chitosan and obtained from $\mathrm{HmbG}$ Reagent Chemicals (Selangor, Malaysia). All the aqueous solutions were prepared using distilled deionized water $\left(18.2 \mathrm{M} \cdot \Omega \mathrm{cm}^{-1}\right)$.

\section{Preparation of magnetite nanoparticles and coating procedure}

The iron oxide nanoparticles were prepared as previously reported by Lee et al. ${ }^{18} \mathrm{~A}$ mixture of $2.43 \mathrm{~g}$ ferrous chloride tetrahydrate $\left(\mathrm{FeCl}_{2} \cdot 4 \mathrm{H}_{2} \mathrm{O}\right), 0.99 \mathrm{~g}$ ferric chloride hexahydrate $\left(\mathrm{FeCl}_{3} \cdot 6 \mathrm{H}_{2} \mathrm{O}\right)$, and $80 \mathrm{~mL}$ of deionized water in the presence of $6 \mathrm{~mL}$ of ammonia hydroxide ( $25 \%$ by mass) was exposed to ultrasonic irradiation for 1 hour. The precipitates were centrifuged and washed with deionized water three times (around 6 minutes for each wash). The washed precipitates were then dispersed in $100 \mathrm{~mL}$ of deionized water and mixed with $1 \%$ chitosan. ${ }^{19}$ After stirring the mixture for 24 hours, the black precipitates were collected using a permanent magnet, washed, and dried in an oven. A $2 \%$ drug solution ${ }^{20,21}$ was prepared in hot ethanol. To obtain 6-mercaptopurine-coated magnetite nanoparticles, the 6-mercaptopurine solution was added to the magnetite chitosan solution, and the mixture was stirred for 24 hours. Finally, the coated magnetite was collected using a permanent magnet, washed with deionized water three times ( 6 minutes for each wash), and dried in an oven. In addition, due to the low percentage loading, another nanocomposite was prepared using the same amount and methods, except that dimethyl sulfoxide was used as the solvent for 6-mercaptopurine (FCMP-D). We compared the two nanocomposites (FCMP and FCMP-D) in terms of their ability to load and release 
6-mercaptopurine and performed an in vitro bioassay for each nanocomposite. Pure 6-mercaptopurine dissolved in hot ethanol designated as MP and pure 6-mercaptopurine dissolved in dimethyl sulfoxide was designated as MP-D. Ultrasonic irradiation resulted in cavitations appearing in the aqueous medium which produced a high temperature (around $5,000^{\circ} \mathrm{C}$ ) and over $1,800 \mathrm{kPa}$, conditions in which many unusual chemical reactions may occur. ${ }^{22}$

\section{Cell viability study}

\section{Cell culture}

Normal mouse fibroblast (3T3) and leukemia (WEHI-3) cell lines were purchased from the American Type Culture Collection (Manassas, VA, USA) and cultured in RPMI (Roswell Park Memorial Institute) 1640 medium (SigmaAldrich) supplemented with 10\% fetal bovine serum (Invitrogen, Auckland, New Zealand) and 1\% antibiotics (100 units $/ \mathrm{mL}$ penicillin and $100 \mu \mathrm{g} / \mathrm{mL}$ streptomycin). The cells were incubated at $37^{\circ} \mathrm{C}$ in humidified $5 \% \mathrm{CO}_{2} / 95 \%$ air, and then used for seeding and treatment at $90 \%$ confluence. The confluent cell layers were removed enzymatically using trypsin-ethylenediamine tetra-acetic acid (Gibco, Grand Island, NY, USA), and resuspended in fresh culture medium. An MTT assay was performed to observe the cytotoxicity of FCMP, pure 6-mercaptopurine, and iron oxide nanoparticles in the two cell lines. In addition, we investigated the cytotoxicity of the FCMP-D nanocomposite in the two cell lines.

\section{Preparation of nanoparticles for viability assay}

Experiments were done in triplicate, and a freshly prepared nanoparticle solution was used to treat the cells each time. The FCMP, FCMP-D nanocomposites and the corresponding empty iron oxide carrier were each dispersed in phosphatebuffered saline. To ensure uniform suspensions, stock suspensions containing $10 \mathrm{mg} / \mathrm{mL}$ of each nanoparticle were created by sonication for 30 minutes and use of culture medium to obtain the desired concentration via serial dilutions. For further dispersion, the nanoparticle solutions were vortexagitated for 2 minutes each time before use. The cells were exposed to doses in the range of $0.47-30 \mu \mathrm{g} / \mathrm{mL}$ for 72 hours to assess the impact of exposure on cell viability. Wells containing cells and medium only were used as the control.

\section{Cytotoxicity assay}

The 3 T3 and WEHI-3 cells ${ }^{23}$ were seeded at a density of $1.0 \times 10^{5}$ cells/well in 96-well plates and kept in 5\% $\mathrm{CO}_{2}$ at $37^{\circ} \mathrm{C}$ for 24 hours, to promote cell attachment. Using a serial dilution dose range of $0.47-30 \mu \mathrm{g} / \mathrm{mL}$ and $0 \mu \mathrm{g} / \mathrm{mL}$ as the control, the cells were left for 72 hours. Cell viability was determined using a colorimetric assay based on conversion of the MTT solution to soluble formazan by viable cells. In brief, $20 \mu \mathrm{L}$ of MTT solution ( $5 \mathrm{mg} / \mathrm{mL}$ in phosphate-buffered saline) was added to each well and left in the incubator for 3 hours. The medium containing MTT was removed gently and replaced with dimethyl sulfoxide (100 $\mu \mathrm{L} /$ well) to mix the formazan crystals until dissolved. Absorbance at $570 \mathrm{~nm}$ and $630 \mathrm{~nm}$ (background) was measured using a microplate enzyme-linked immunosorbent assay reader (ELx800, BioTek Instruments, Winooski, VT, USA). All experiments were carried out in triplicate and the results are presented as the mean \pm standard deviation.

\section{Drug-release procedure}

To study the release process, two $\mathrm{pH}$ levels ( 7.4 and 4.8) were used because of their similarity to the $\mathrm{pH}$ of blood and that of the stomach. The $\mathrm{pH}$ of blood was adjusted to a narrow slightly alkaline range of 7.35-7.45, and changing this range may have fatal consequences. The $\mathrm{pH}$ of the stomach varies from $1-2$ to $4-5$, and is normally about 5-6 before ingestion of food. Proteases and hydrochloric acid are released in the stomach to aid digestion after a meal, and proteases cleave proteins better in an acidic environment. Therefore, after a high-protein meal, the $\mathrm{pH}$ of the stomach decreases to 1-2. Meanwhile, buffering increases the $\mathrm{pH}$ back to 3-4. After digestion, $\mathrm{pH}$ returns to a resting level of around 4-5. ${ }^{24}$

To study the controlled-release properties of MP and MP-D, different anions, including $\mathrm{Cl}^{-}, \mathrm{HPO}_{4}{ }^{2-}$ and $\mathrm{H}_{2} \mathrm{PO}_{4}^{-}$, which affect the rate of drug release, were used to observe the release characteristics of the drug-coated samples. Therefore, the release profiles of MP and MP-D from the two nanocomposites, ie, FCMP and FCMP-D, were determined at $25^{\circ} \mathrm{C}$ using aqueous buffered solutions of $\mathrm{pH} 4.8^{25,26}$ and $\mathrm{pH} 7.4,{ }^{27}$ and the blank solutions used were $\mathrm{pH} 4.8$ and $\mathrm{pH}$ 7.4 , respectively. The ultraviolet-visible spectrum of MP and MP-D shows intense absorbance at $330 \mathrm{~nm}$. Therefore, the MP and MP-D released were measured at predetermined time points using an ultraviolet-visible spectrophotometer at $330 \mathrm{~nm}$. About $10 \mathrm{mg}$ of the FCMP nanocomposite was added to $25 \mathrm{~mL}$ of $\mathrm{Na}_{2} \mathrm{CO}_{3}(1 \mathrm{M})$ and stirred for 24 hours, and the amount of MP released was measured at a $\lambda_{\text {max }}$ of $330 \mathrm{~nm}$. For the FCMP-D nanocomposite, the same methods and amounts of nanocomposite were used.

\section{Characterization}

Using a diffractometer (XRD-6000, Shimadzu, Tokyo, Japan), powder X-ray diffraction patterns were recorded to determine 
the crystal structure of the samples over a temperature range of $4^{\circ} \mathrm{C}-70^{\circ} \mathrm{C}$ using $\mathrm{CuK}_{\alpha}$ radiation $(\lambda=1.5406 \AA)$ at $40 \mathrm{kV}$ and $30 \mathrm{~mA}$. Fourier transform infrared spectroscopy of the materials was performed over the range of $400-4,000 \mathrm{~cm}^{-1}$ using a spectrophotometer (1752X, Perkin-Elmer, Waltham, MA, USA) with the $\mathrm{KBr}$ disc method. Thermogravimetric and differential thermogravimetric analyses were carried out using a Mettler Toledo instrument (Longview, WA, USA) in $150 \mu \mathrm{L}$ alumina crucibles in the temperature range of $20^{\circ} \mathrm{C}-1,000^{\circ} \mathrm{C}$. The mean particle size, size distribution, and morphology of the samples were observed using a transmission electron microscope (H-7100, Hitachi, Tokyo, Japan) at an accelerating voltage of $100 \mathrm{kV}$ and $150 \mathrm{kV}$.

\section{Results and discussion X-ray diffraction}

Figure 1 shows the X-ray diffraction patterns for the naked iron oxide nanoparticles (Figure 1A), FCMP (Figure 1B), and pure chitosan and MP. The X-ray diffraction spectrum for pure chitosan (Figure 1C) shows two main $2 \theta$ diffraction peaks at $10.5^{\circ}$ and $20.6^{\circ} \cdot{ }^{28-30}$ The diffraction pattern for pure 6 -mercaptopurine indicated distinct peaks at $2 \theta=11.8^{\circ}$, $14.6^{\circ}, 16.8^{\circ}, 21.2^{\circ}, 23.5^{\circ}, 25.3^{\circ}, 25.9^{\circ}, 27.5^{\circ}, 29.5^{\circ}$, and $30.3^{\circ}$ (Figure 1D). Naked iron oxide showed six intense peaks between $30^{\circ} \mathrm{C}$ and $70^{\circ} \mathrm{C}$ that could be assigned as (220),

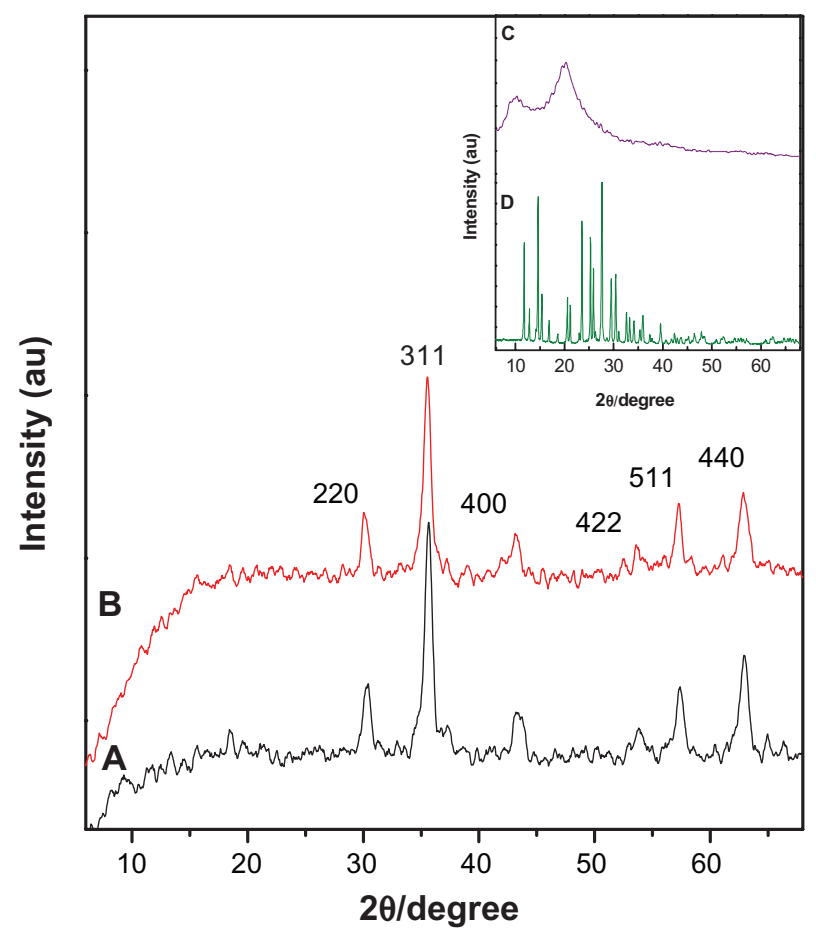

Figure I X-ray diffraction patterns for iron oxide $(\mathbf{A})$ and iron oxide coated with chitosan and 6-mercaptopurine (FCMP) (B). Inset shows X-ray diffraction pattern for pure chitosan (C) and pure 6-mercaptopurine (D).
(311), (400), (422), (511), and (440). These six diffraction peaks for pure iron oxide (JCPDS No 19-629) confirmed that the magnetite nanoparticles were pure iron oxide with a cubic inverse spinal structure. These characteristic peaks were observed in both samples (Figure 1A and B), confirming that the coating process did not affect any phase change in the iron oxide. According to the Debye-Scherrer equation $(\mathrm{D}=\mathrm{K} \lambda / \beta \cos \theta),{ }^{4,31-33}$ the mean crystallite size $(\mathrm{D})$ is calculated, where $\mathrm{K}$ is the Debye-Scherrer constant $(0.9), \lambda$ is the X-ray wavelength $(0.15406 \mathrm{~nm}), \beta$ is the peak width of half-maximum, and $\theta$ is the diffraction angle. Using the $\mathrm{X}$-ray results and Debye-Scherrer equation, the particle size of the pure iron oxide was about $4 \mathrm{~nm}$.

\section{Fourier transform infrared spectra}

The Fourier transform infrared spectra for the five samples are shown in Figure 2. The broad absorption peak observed at around $3,429 \mathrm{~cm}^{-1}$ (Figure 2A and C) is assigned to $\mathrm{O}-\mathrm{H}$ stretching. ${ }^{34}$ The peak at around $560 \mathrm{~cm}^{-1}$ (Figure 2A and $\mathrm{C}$ ) relates to the $\mathrm{Fe}-\mathrm{O}$ group. On the other

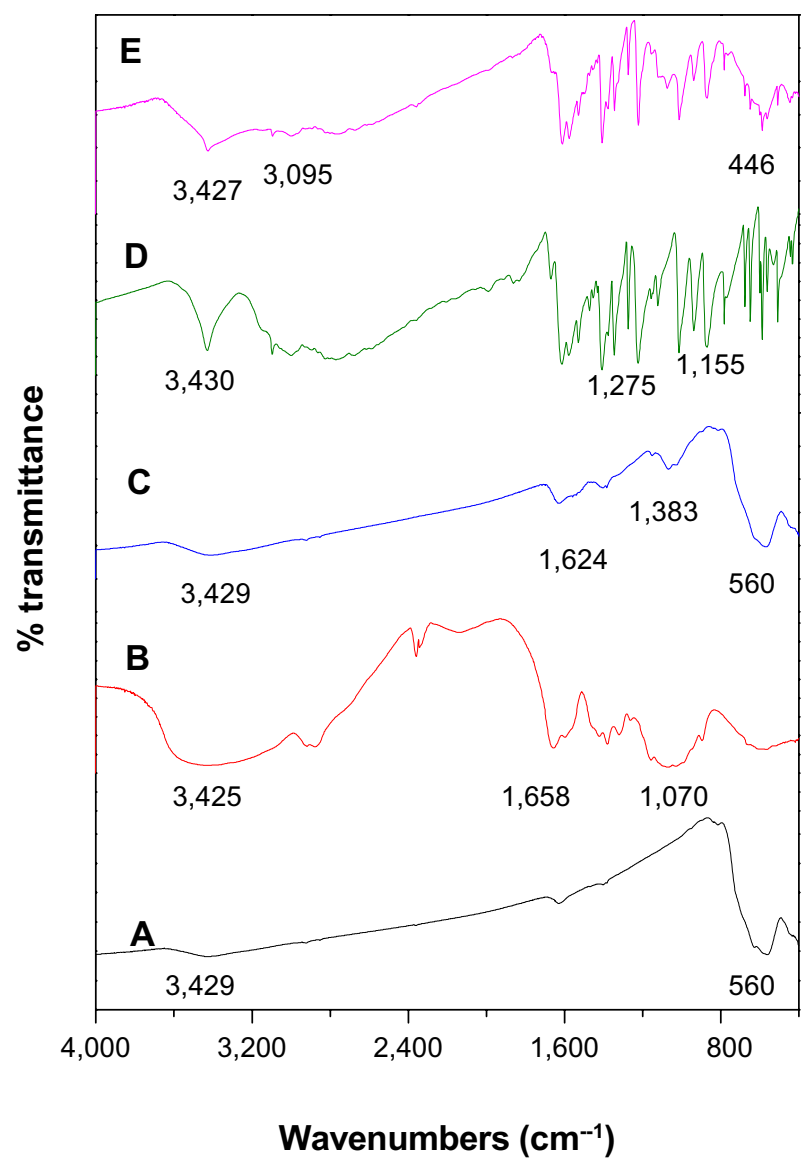

Figure 2 Fourier transform infrared spectra for (A) iron oxide nanoparticles, (B) chitosan, (C) iron oxide nanoparticles coated with chitosan, (D) pure 6-mercaptopurine, and (E) FCMP, iron oxide nanoparticles coated with chitosan and 6-mercaptopurine. 
hand, the band at $446 \mathrm{~cm}^{-1}$ in the low energy range might be related to the $v_{\mathrm{Fe}-\mathrm{S}}$ and $v_{\mathrm{Fe}-\mathrm{N}}$ vibration modes (Figure $2 \mathrm{E}$ ). In Figure $2 \mathrm{C}$, the main characteristic absorption bands appearing at $1,624 \mathrm{~cm}^{-1}$ and $1,383 \mathrm{~cm}^{-1}$ can be assigned to $\mathrm{N}-\mathrm{H}$ bending vibration and $-\mathrm{C}-\mathrm{O}$ stretching of the alcohol group in chitosan, respectively. Figure $2 \mathrm{~B}$ shows the characteristic bands of pure chitosan at around $3,425 \mathrm{~cm}^{-1}(\mathrm{O}-\mathrm{H}$ stretching and N-H stretching vibrations), $1,658 \mathrm{~cm}^{-1}$ (amide), and $1,064 \mathrm{~cm}^{-1}(\mathrm{C}-\mathrm{O}-\mathrm{C}$ stretching vibration). The absence of a band at $1,155 \mathrm{~cm}^{-1}\left(\mathrm{v}_{\mathrm{C}=\mathrm{s}} /\right.$ ring vibration $)$ in Figure $2 \mathrm{E}$ suggests participation of an exocyclic (S) atom in metallic bonding of the heterocyclic ligand in the Fe (II) coordination compound. ${ }^{16}$ The peak at $3,095 \mathrm{~cm}^{-1}$ belongs to the $\mathrm{v}_{\mathrm{C}-\mathrm{H}}$ aromatic (Figure 2E). The peak observed in Figure 2D for pure 6-mercaptopurine at around $1,275 \mathrm{~cm}^{-1}$ can be assigned to the $\mathrm{C}=\mathrm{S}$ group and the absence of this absorption peak at $1,275 \mathrm{~cm}^{-1}$ in the FCMP compound confirms formation of the 6-mercaptopurine complex via the sulfur atom (Figure 2E). ${ }^{16}$ As could be observed, chitosan and 6-mercaptopurine were successfully coated to the iron oxide nanoparticles.

\section{Magnetic properties}

Figure 3 shows the hysteresis loops for naked iron oxide nanoparticles (Figure 3A) and iron oxide nanoparticles coated with chitosan and 6-mercaptopurine (Figure 3B), which were characterized using a vibrating sample magnetometer at room temperature. The values for saturation magnetization and remanent magnetization are shown in Table 1. Using the sonochemical method, the saturation magnetization of the magnetite nanoparticles was about $29.09 \mathrm{emu} / \mathrm{g}$ compared with $17.50 \mathrm{emu} / \mathrm{g}$ for FCMP, which agrees well with previous work. ${ }^{35}$ It was demonstrated that both types of magnetic nanoparticles had superparamagnetic characteristics, meaning that they do not retain any magne-

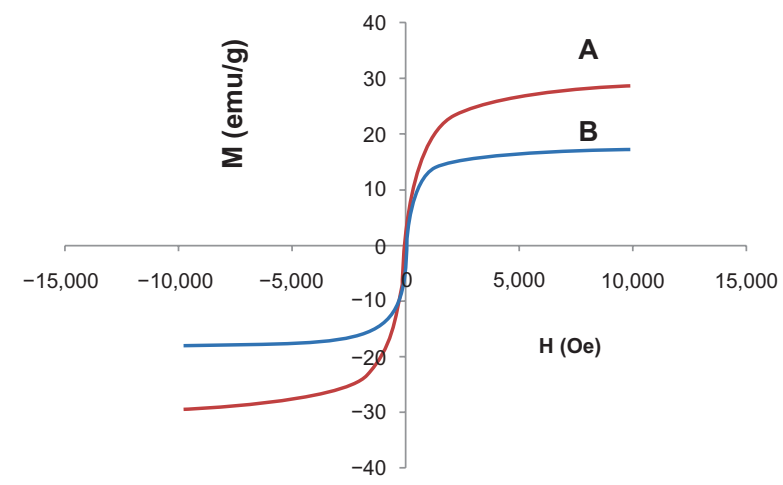

Figure 3 Magnetization plots of (A) iron oxide magnetite nanoparticles and (B) iron oxide nanoparticles coated with chitosan and 6-mercaptopurine.

Notes: The data is presented in terms of $M$, mass magnetization (emu/g), versus $\mathrm{H}$, applied magnetic field (Oe).
Table I Magnetic properties of $\mathrm{Fe}_{3} \mathrm{O}_{4}$ magnetite nanoparticles and FCMP

\begin{tabular}{lll}
\hline Samples & $\mathbf{M}_{\mathbf{s}}(\mathrm{emu} / \mathbf{g})$ & $\mathbf{M}_{\mathbf{r}}(\mathrm{emu} / \mathbf{g})$ \\
\hline $\mathrm{Fe}_{3} \mathrm{O}_{4}$ & 29.091 & 1.098 \\
$\mathrm{FCMP}$ & 17.497 & 0.365 \\
\hline
\end{tabular}

Abbreviations: FCMP, iron oxide nanoparticles coated with chitosan and 6-mercaptopurine; $M_{r}$, remanent magnetization; $M_{s}$, saturation magnetization.

tism after removal of a magnetic field. The decreased saturation magnetization could be due to the existence of coated materials on the surfaces of the magnetite nanoparticles. ${ }^{36}$ A high degree of magnetization and superparamagnetic properties are in high demand for biomedical applications because the larger magnetic particles form aggregates after exposure to a magnetic field.

\section{Thermogravimetric analyses}

Thermogravimetric and differential thermogravimetric analyses (TGA-DTG) is a technique measuring physical changes in materials. It enables quantitative measurement of percent weight loss from a sample associated with transition and thermal degradation in a controlled environment. Thermal analysis is usually recorded as change in mass from decomposition, dehydration, and oxidation of a sample, as related to thermal stability at selected temperatures, usually between $25^{\circ} \mathrm{C}$ and $1,000^{\circ} \mathrm{C}$. The thermogram data changed because of the unique physicochemical reactions that occur in this temperature range. These characteristics are relevant to the molecular structure of the sample. The TGA-DTG analyses for pure 6-mercaptopurine and FCMP nanoparticles was obtained under atmospheric conditions (Figure 4). For free 6-mercaptopurine, the thermal behavior indicates three stages of weight loss (Figure 4A). At $158^{\circ} \mathrm{C}$, a total weight loss of $11 \%$ was observed, and is attributed to removal of crystalline water. The second sharp mass reduction step at $328^{\circ} \mathrm{C}(31.2 \%)$ corresponds to decomposition of 6-mercaptopurine. This temperature agrees well with the value of $320^{\circ} \mathrm{C}-350^{\circ} \mathrm{C}$ recorded for the decomposition of 6-mercaptopurine. ${ }^{17}$ Although the mass fragmentation process and thermal decomposition is not exactly the same, the weight loss observed may be due to loss of an HCS group at this step, corresponding to the fragmentation of heterocyclic compounds seen on mass spectroscopy. The differential thermogravimetric curve shows one peak at $663^{\circ} \mathrm{C}$. The curve shape on TGA-DTG was changed due to the chitosan coating (Figure 4B). The thermal behavior of FCMP shows that the stages of mass loss occur at $50^{\circ} \mathrm{C}-900^{\circ} \mathrm{C}$. The first stage of mass loss starts at $4{ }^{\circ} \mathrm{C}-131^{\circ} \mathrm{C}$ and is attributable to removal of adsorbed 

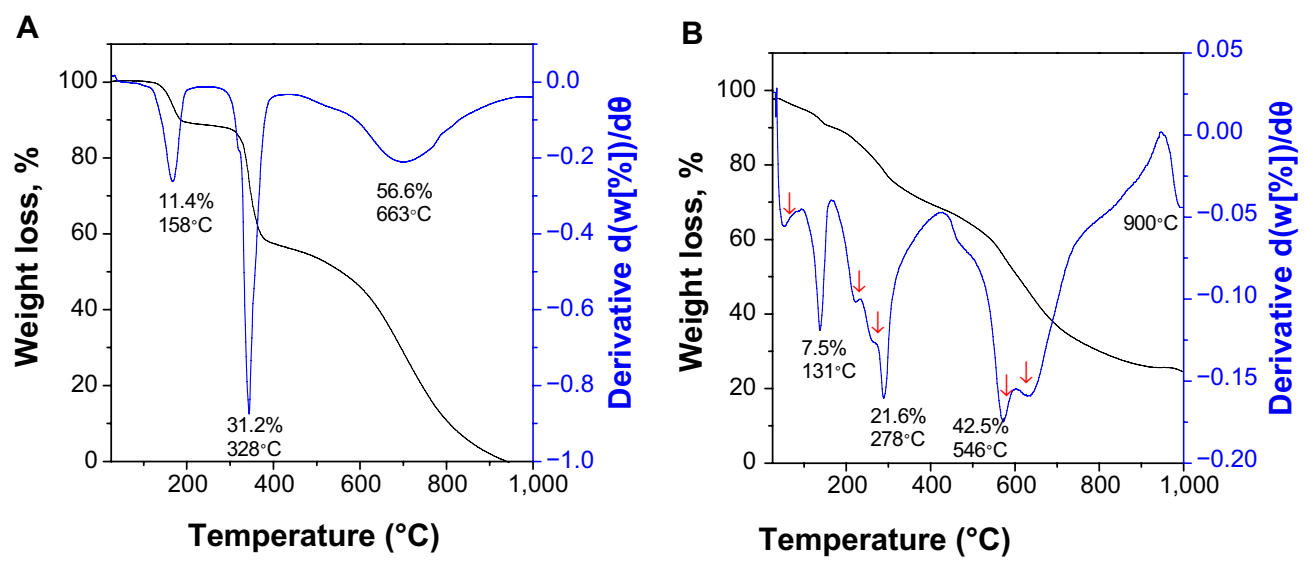

Figure 4 Thermogravimetry analyses of (A) 6-mercaptopurine and (B) iron oxide nanoparticles coated with chitosan and 6-mercaptopurine. Note: The red arrows point to the weight loss.

water. The onset of decomposition of free drug, iron oxide, and FCMP was observed in three stages of weight loss between $214^{\circ} \mathrm{C}$ and $278^{\circ} \mathrm{C}(21.6 \%$ weight loss $)$. After that, two stages of mass reduction were observed between $546^{\circ} \mathrm{C}$ to $650^{\circ} \mathrm{C}$, which may be due to decomposition of chitosan coated with MP and also the uncoated free drug. It should be noted that the temperature range for FCMP was markedly higher than that for pure free 6-mercaptopurine, indicating that the coating of the magnetite nanocomposite resulted in enhanced thermal stability.

\section{Determination of average size and size distribution properties}

Transmission electron microscopy was used to obtain more information about the size and uniformity of particles synthesized under optimum conditions. The size of the iron oxide particles and FCMP can be seen in Figure 5A and B, respectively. The particle size and size distribution of the iron oxide nanoparticles and FCMP were calculated from at least 200 particles chosen at random using image analysis software (UTHSCSA ImageTool). From the images, it is obvious that the as-synthesized iron oxide nanoparticles and the FCMP nanocomposite were mostly spherical. Figure 5 shows that these particles had a very small size range of around 9-19 $\mathrm{nm}$ in diameter with a narrow size distribution. The average particle size of the iron oxide magnetite nanoparticles was $9 \pm 2 \mathrm{~nm}$ (Figure 5C), whereas after coating with chitosan and 6-mercaptopurine, the mean size of the FCMP increased to $19 \pm 4 \mathrm{~nm}$ (Figure 5D). Enlargement of the size of FCMP confirms formation of iron oxide nanoparticles coated with chitosan and 6-mercaptopurine. It can be seen that the iron oxide nanoparticles tended to aggregate because of their large specific surface area, high surface energy, and magnetization effect. ${ }^{37}$

\section{Loading and release behavior of 6-mercaptopurine}

Using the ultraviolet instrument and calibration curve equation, loading of 6-mercaptopurine into the FCMP nanocomposite using hot ethanol as the solvent (MP) was around $5 \%$ compared with $33 \%$ when the solvent was changed to dimethyl sulfoxide (MP-D). Therefore, the release properties of MP from the FCMP nanocomposite were investigated further for nanocomposites in phosphate-buffered solution at $\mathrm{pH} 4.8$ and 7.4. The release profiles for the physical mixture of 6-mercaptopurine in $\mathrm{pH} 4.8$ and $\mathrm{pH} 7.4$ buffer solutions are shown in Figure 6A. It was found that 6-mercaptopurine was rapidly released from the physical mixture and that release was complete within 1 and 4 minutes at $\mathrm{pH} 4.8$ and $\mathrm{pH} 7.4$, respectively. This was because of the low electrostatic attraction between the 6-mercaptopurine anions and iron oxide-chitosan nanoparticles.

Figure 6B (I and II) shows the release rate of MP into buffer solutions at $\mathrm{pH} 4.8$ and 7.4, respectively, and indicate that the MP release profiles from FCMP depend on $\mathrm{pH}$. The release rate at $\mathrm{pH} 7.4$ is substantially lower than that at $\mathrm{pH}$ 4.8. The slow and sustained release observed may be due to the ion-exchange process taking place between the 6-mercaptopurine anions and the anions in the buffer solutions. ${ }^{38-40}$

The maximum percent release of MP from the FCMP nanocomposite reached $93.2 \%$ and $50.6 \%$ in about 120 and 70 minutes when the sample was exposed to $\mathrm{pH} 4.8$ and 7.4, respectively. Figure 6B (I) shows that release in $\mathrm{pH} 4.8$ solution was very rapid for the first 60 minutes, which can be attributed to partial dissolution of the FCMP nanocomposite in an acidic environment. ${ }^{39,41}$ Figure $6 \mathrm{C}$ shows the release rate for MP-D into buffer solutions at $\mathrm{pH}$ 4.8 and 7.4. The maximum percent release of MP-D from 

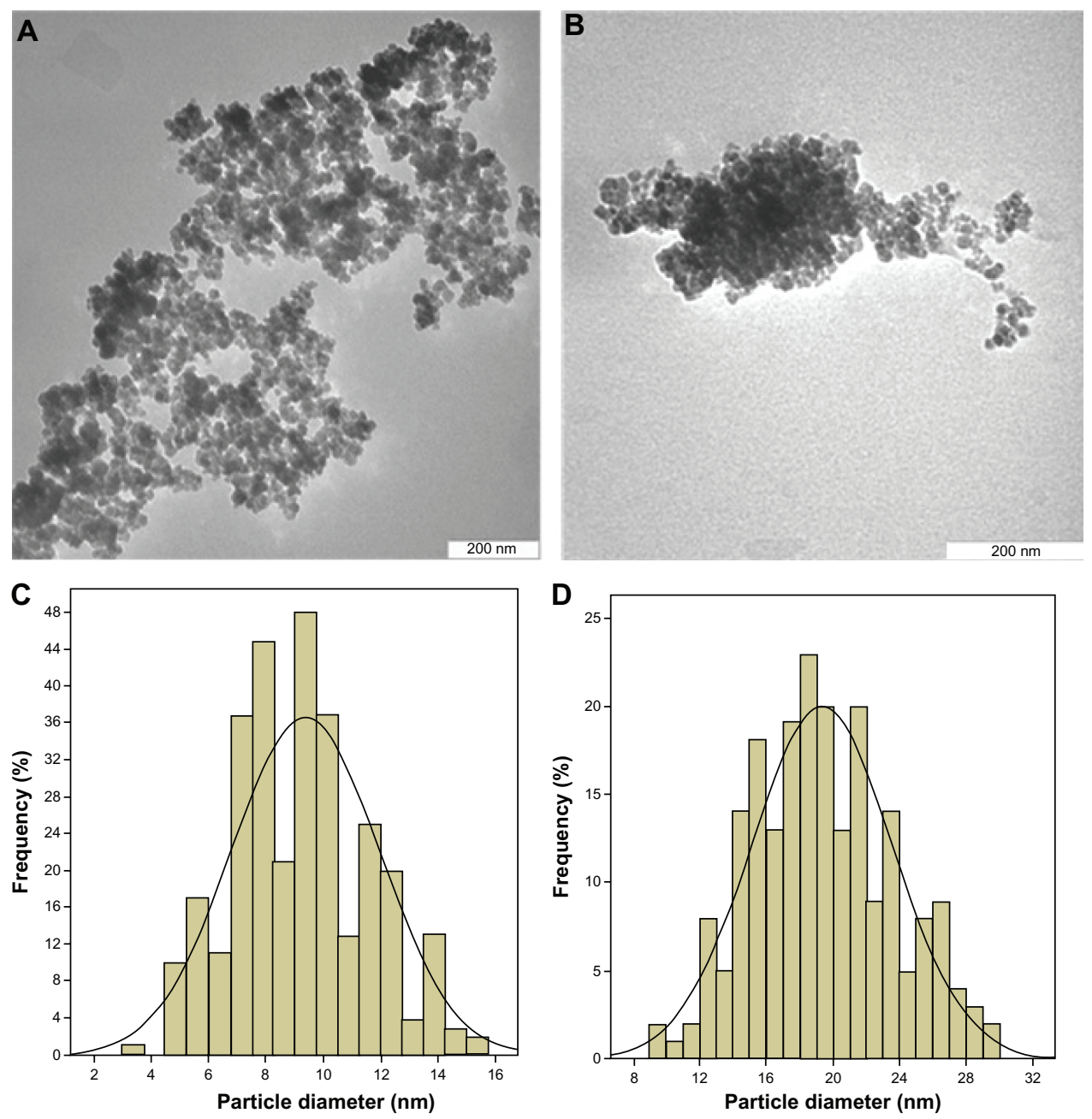

Figure 5 Transmission electron micrographs for (A) iron oxide magnetite nanoparticles (200 nm bar), (B) iron oxide nanoparticles coated with chitosan and 6-mercaptopurine (200 nm bar), particle size distribution of iron oxide nanoparticles (C) and particle size distribution of iron oxide nanoparticles coated with chitosan and 6-mercaptopurine (D).

the FCMP-D nanocomposite reached $97.7 \%$ and $55.4 \%$ within about 2,500 and 6,300 minutes when exposed to $\mathrm{pH} 4.8$ and 7.4, respectively. It was also observed that the MP-D nanocomposite released the active drug in a more sustained manner compared with MP. Of note, there was no initial burst release, with release starting after 35 minutes at pH 4.8 compared with 88 minutes at pH 7.4 (Figure 6C). It was also seen that the percentage of the active MP released from FCMP and FCMP-D at equilibrium did not reach $100 \%$. This trend was probably due to the characteristics of the ion-exchange reaction, ie, the equilibrium process and the coated anions cannot be exchanged completely, but the organic species released is removed or consumed continuously. ${ }^{27}$

Therefore, these differences in the rate of release of the active drug at $\mathrm{pH} 4.8$ and 7.4 are presumably due to the different release mechanism of 6-mercaptopurine in the coating structure of the nanocomposite. Further, FCMP and FCMP-D nanocomposites are more stable at $\mathrm{pH} 7.4$, and the release of the active MP would have occurred via an anion exchange process. In addition, rapid release of the active MP (around 30\%, Figure 6B (II)) in the first 5 minutes might be due to the free uncoated drug, as indicated in the thermal analysis studies.

\section{Kinetics of 6-mercaptopurine release from the nanocomposite}

The release kinetics of 6-mercaptopurine (MP and MP-D) from the FCMP and FCMP-D nanocomposites were investigated further using different kinetic models, ie, first-order ${ }^{42}$ (equation 1), pseudo-second $\operatorname{order}^{43}$ (equation 2), and parabolic diffusion $^{44}$ (equation 3):

$$
\ln \left(\mathrm{q}_{\mathrm{e}}-\mathrm{q}_{\mathrm{t}}\right)=\ln \mathrm{q}_{\mathrm{e}}-\mathrm{k}_{1} \mathrm{t}
$$


A
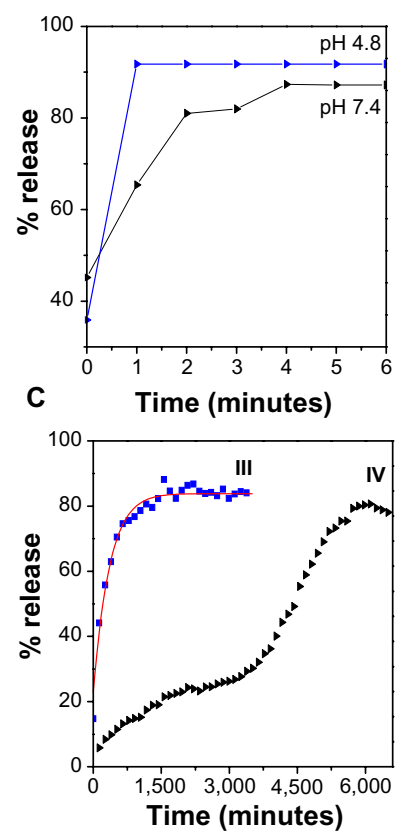

Figure 6 (A) Release profiles for physical mixtures of 6-mercaptopurine and (B) 6-mercaptopurine from iron oxide nanoparticles coated with chitosan and 6-mercaptopurine dissolved in hot ethanol into (I) phosphate-buffered solution at $\mathrm{pH}$ 4.8, (II) phosphate-buffered solution at $\mathrm{pH} 7.4$, and (C) release profiles for 6-mercaptopurine from the iron oxide nanoparticles containing the same amounts of chitosan and 6-mercaptopurine dissolved in dimethyl sulfoxide into (III) phosphatebuffered solution at $\mathrm{pH} 4.8$ and (IV) phosphate-buffered solution at $\mathrm{pH}$ 7.4.

$$
\begin{gathered}
\mathrm{t} / \mathrm{q}_{\mathrm{t}}=1 / \mathrm{k}_{2} \mathrm{q}_{\mathrm{e}}^{2}+\mathrm{t} / \mathrm{q}_{\mathrm{e}} \\
\left(1-\mathrm{M}_{\mathrm{t}} / \mathrm{M}_{0}\right) / \mathrm{t}=\mathrm{kt}^{-0.5}+\mathrm{b}
\end{gathered}
$$

where $\mathrm{q}_{\mathrm{e}}$ and $\mathrm{q}_{\mathrm{t}}$ are the equilibrium release rate and the release rate at time $\mathrm{t}$, respectively, $\mathrm{k}$ is a constant corresponding to release amount, and $\mathrm{M}_{0}$ and $\mathrm{M}_{\mathrm{t}}$ represent the drug content remaining in FCMP/FCMP-D at release time 0 and $t$, respectively, and $\mathrm{b}$ is a constant.

Fitting the data for release of the active MP to these three kinetic models, it was found that the pseudo-second order model was best able to describe the release kinetic processes of MP from the FCMP nanocomposite at both $\mathrm{pH}$ levels compared with the other models. Figure 7A shows that, for phosphate-buffered solution at $\mathrm{pH} 4.8$, the pseudo-second order model fits better to the data (correlation coefficient, $R^{2}$, with $\mathrm{K}$ values of 0.9914 and $6.73 \times 10^{-4} \mathrm{mg}$ per minute, respectively). At $\mathrm{pH} 7.4$, release of MP from FCMP also followed the pseudo-second order equation, with a correlation coefficient of 0.9965 (Figure 7B). The release of MP-D from FCMP-D did not obey either pseudo-second order $\left(R^{2}=0.1109\right)$ or parabolic order kinetics. For the FCMP-D nanocomposite, it can be observed that the pseudo-second order model gives a better fit for phosphate-buffered solution at pH 4.8 (Figure 7C). However, phosphate-buffered solution at $\mathrm{pH} 7.4$ is better fitted to the first order kinetic model (Figure 7D). Table 2 indicates the time release profile for MP and MP-D in phosphate-buffered solutions at $\mathrm{pH} 7.4$ and 4.8 in FCMP and FCMP-D, respectively.

\section{In vitro bioassay}

Figure 8 shows the viability assays for normal mouse fibroblast cells (Figure 8A) and the anticancer activity of FCMP, FCMP-D, iron oxide nanoparticles, and pure 6-mercaptopurine, respectively (Figure 8B) 72 hours post treatment. Normal mouse fibroblast cells exposed to increasing concentrations $(0.47-30 \mu \mathrm{g} / \mathrm{mL})$ of FCMP, FCMP-D, iron oxide nanoparticles, and pure 6-mercaptopurine did not show a decrease in viability compared with untreated control cells at 72 hours posttreatment. Viability of leukemia cells was found to be reduced to less than $20 \%$ following incubation with pure 6-mercaptopurine, FCMP, and FCMP-D at $30 \mu \mathrm{g} / \mathrm{mL}$ after 72 hours. Exposure to the empty carrier, ie, iron oxide nanoparticles, resulted in sustained viability of the leukemia cells, with more than $70 \%$ of cells remaining viable, even at a concentration of $30 \mu \mathrm{g} / \mathrm{mL}$ after 72 hours. Lower percent viability was observed following incubation of the leukemia cells with pure MP than with FCMP and FCMPD nanoparticles.

Using this viability (MTT) study, the newly synthesized FCMP and FCMP-D nanoparticles showed efficacy in the leukemia cell line in a dose-dependent manner, the pattern of which resembles that for MP (Figure 8A). On the other hand, iron oxide nanoparticles had a negligible effect in the same cancer cell line, with almost $100 \%$ of cells remaining viable at $15 \mu \mathrm{g} / \mathrm{mL}$ compared with about $25 \%$ and $15 \%$ of cells remaining viable at $15 \mu \mathrm{g} / \mathrm{mL}$ of FCMP and FCMP$\mathrm{D}$, respectively. Thus, the cytotoxicity to leukemia cells is likely attributable to release of MP from the carrier rather than the effect of the carrier itself. This result indicates that the anticancer activity of our new compound is very similar to that of pure MP and suggests the possibility of a decreased dosing interval due to the sustained-release ability of the nanoparticles. With the sustained release and possible targeted delivery potential of these nanoparticles, the least amount of active agent (6-mercaptopurine) could suffice, hence reducing the dosing interval and unnecessary exposure to large quantities of this hazardous drug. The results further suggest the possibility of increased anticancer activity with increasing the loading percentage. A previous study showed good anticancer activity in a HeLa 
A

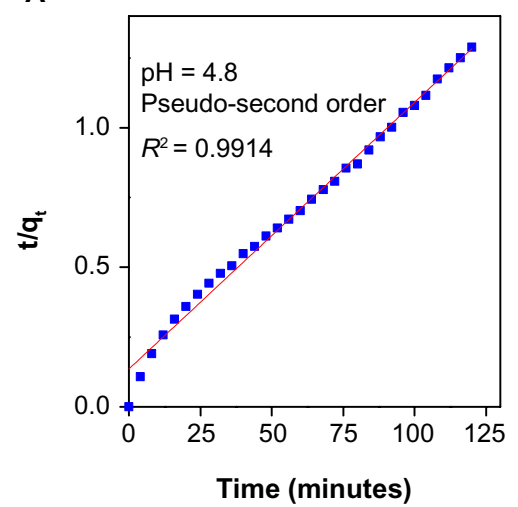

C

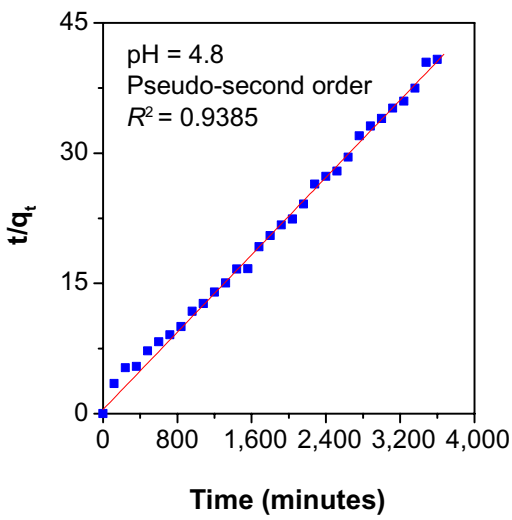

B

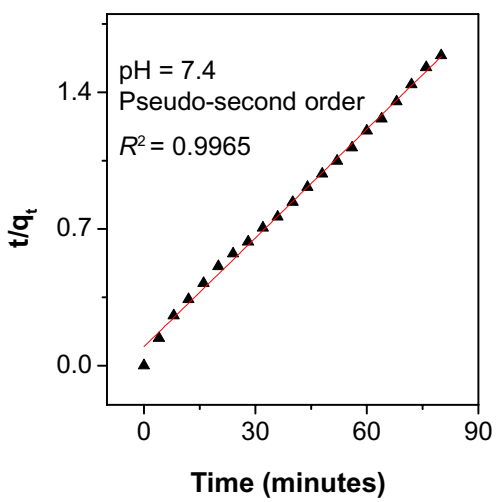

D

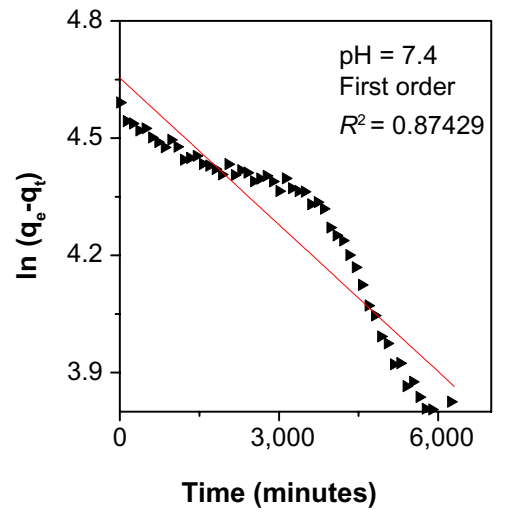

Figure 7 Fitting the data for 6-mercaptopurine release from iron oxide nanoparticles coated with chitosan and 6-mercaptopurine dissolved in hot ethanol into different solutions to the pseudo-second order kinetics for $\mathrm{pH} 4.8(\mathbf{A})$ and $\mathrm{pH} 7.4(\mathbf{B})$ and fitting data of 6-mercaptopurine released from the iron oxide nanoparticles coated with chitosan and 6-mercaptopurine dissolved in dimethyl sulfoxide into different solutions to the pseudo-second order kinetics for $\mathrm{pH} 4.8$ (C) and first order kinetics for $\mathrm{pH} 7.4$ (D).

Abbreviations: $t$, time; $q_{t}$, release at time $t$.

(cervical cancer) cell line using a synthesized complex of MP and two metals (silver and gold). ${ }^{45}$ Similar anticancer activity was demonstrated in an HT29 cell line using solid lipid nanoparticles, where the trypan blue assay was used, indicating improved efficacy for doxorubicin-loaded solid lipid nanoparticles in comparison with the commercially available free counterpart, ie, doxorubicin. ${ }^{46}$
The sustained viability of normal mouse fibroblasts is shown in Figure 8A. Despite increasing concentrations of FCMP and FCMP-D (using the MTT assay), there was minimal or no toxicity in this cell line over the concentration range tested. Thus, FCMP and FCMP-D likely represent alternative drug delivery systems for the treatment of cancer, with the added possibility of

Table 2 Correlation coefficient, rate constant, and elimination half-life obtained by fitting the data for release of MP and MP-D from FCMP and FCMP-D into phosphate-buffered solution at $\mathrm{pH} 4.8$ and $\mathrm{pH} 7.4$

\begin{tabular}{|c|c|c|c|c|c|c|c|}
\hline \multirow[b]{2}{*}{ Sample } & \multirow[b]{2}{*}{$\begin{array}{l}\text { Aqueous } \\
\text { solution }\end{array}$} & \multirow[b]{2}{*}{$\begin{array}{l}\text { Saturated } \\
\text { release \% }\end{array}$} & \multicolumn{3}{|c|}{$R^{2}$} & \multirow[b]{2}{*}{$\begin{array}{l}\text { Rate constant }(\mathrm{K}) \\
(\mathrm{mg} / \mathrm{min})\end{array}$} & \multirow[b]{2}{*}{$\begin{array}{l}t_{1 / 2} \\
(\min )\end{array}$} \\
\hline & & & $\begin{array}{l}\text { Pseudo-first } \\
\text { order }\end{array}$ & $\begin{array}{l}\text { Pseudo-second } \\
\text { order }\end{array}$ & $\begin{array}{l}\text { Parabolic } \\
\text { diffusion }\end{array}$ & & \\
\hline FCMP & $\mathrm{pH} 4.8$ & 93.2 & 0.9624 & 0.9914 & 0.7380 & $\mathrm{a} 6.73 \times 10^{-4}$ & 14 \\
\hline FCMP & $\mathrm{pH} 7.4$ & 50.6 & 0.5055 & 0.9965 & 0.6839 & b $3.52 \times 10^{-3}$ & 5 \\
\hline FCMP-D & $\mathrm{pH} 4.8$ & 97.7 & 0.4853 & 0.9385 & 0.6255 & $2.65 \times 10^{-4}$ & 42 \\
\hline FCMP-D & $\mathrm{pH} 7.4$ & 55.4 & 0.8743 & 0.1109 & 0.8154 & $\mathrm{~d} .25 \times 10^{-4}$ & 5,529 \\
\hline
\end{tabular}

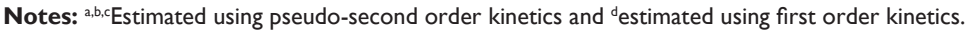

Abbreviations: FCMP, iron oxide nanoparticles coated with chitosan and 6-mercaptopurine dissolved in hot ethanol; FCMP-D, iron oxide nanoparticles containing the same amounts of chitosan and 6-mercaptopurine but dissolved in dimethyl sulfoxide; MP, 6-mercaptopurine dissolved in hot ethanol; MP-D, 6-mercaptopurine dissolved in dimethyl sulfoxide; $\mathrm{t}_{1 / 2}$, elimination half-life. 

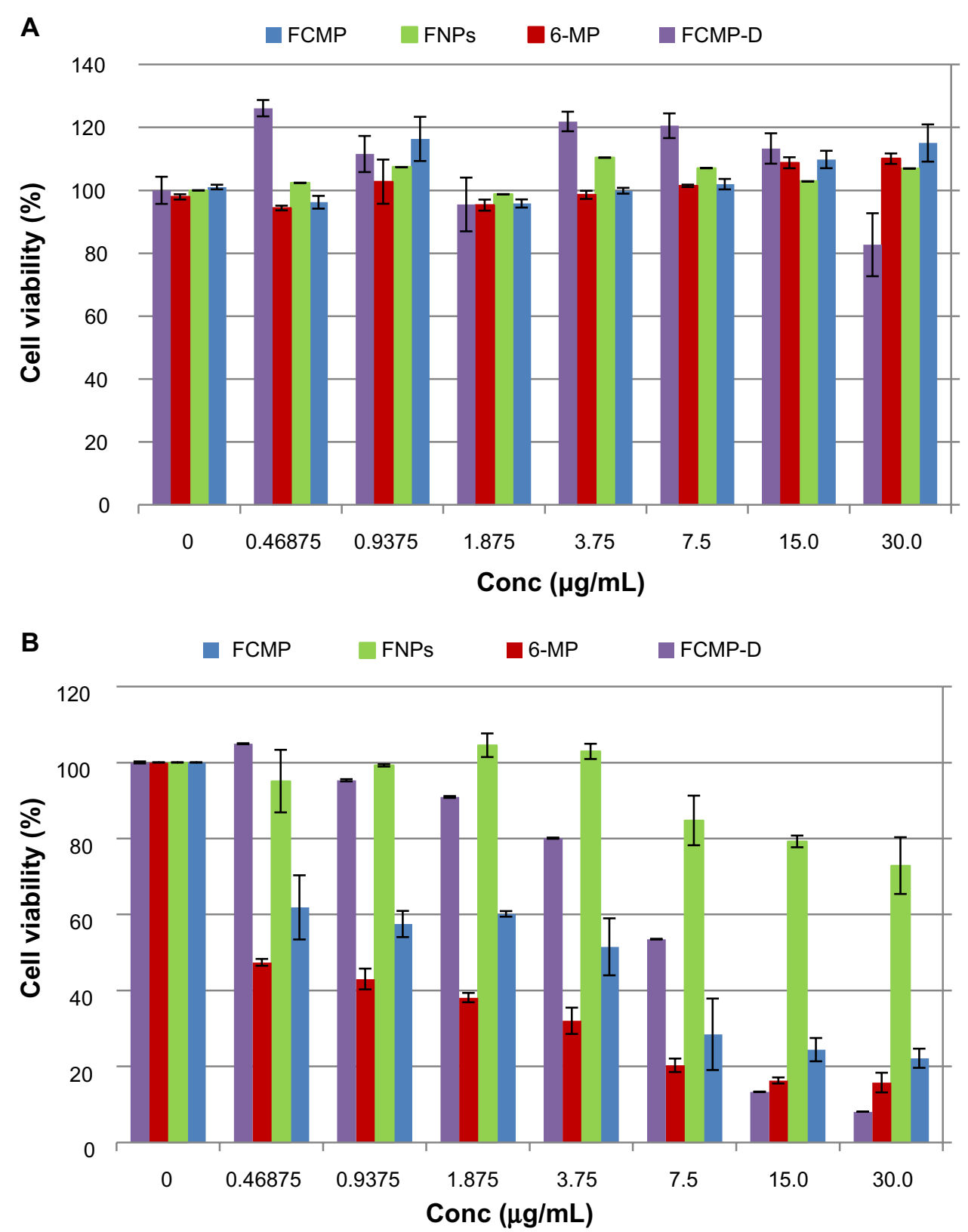

Figure 8 Viability assays for (A) normal mouse fibroblast (3T3) and (B) leukemia (WEHI-3) cell lines and anticancer activity of FCMP, FCMP-D, FNPs, and pure 6-MP, respectively, after 72 hours of treatment. The $\mathrm{IC}_{50}$ was $4.94 \pm 0.76 \mu \mathrm{g} / \mathrm{mL}, 11.94 \pm 0.45 \mu \mathrm{g} / \mathrm{mL}, 47.56 \pm 2.13 \mu \mathrm{g} / \mathrm{mL}$, and $0.60 \pm 0.18 \mu \mathrm{g} / \mathrm{mL}$ for cancer cells exposed to FCMP, FCMP-D, FNPs, and pure 6-MP, respectively.

Abbreviations: FCMP, iron oxide coated with chitosan and 6-mercaptopurine; FNPs, iron oxide nanoparticles; FCMP-D, iron oxide nanoparticles containing the same amounts of chitosan and 6-mercaptopurine but dissolved in dimethyl sulfoxide; Conc, concentration; IC ${ }_{50}$, half maximal inhibitory concentration; 6-MP, 6-mercaptopurine.

sparing healthy surrounding cells and tissue. To check for a toxic effect of nonfunctionalized iron oxide, a dose range of $0.47-30 \mu \mathrm{g} / \mathrm{mL}$ was used in normal fibroblasts, as shown in Figure 8A. As with FCMP and FCMP-D, the nonfunctionalized iron oxide nanoparticles demonstrated no toxicity in this cell line. Viability was shown to be maintained above $90 \%$ compared with the controls. Several cancerous and normal cell lines exposed to iron oxide at doses higher than $30 \mu \mathrm{g} / \mathrm{mL}$ have demonstrated viability above $80 \%$ at 72 hours post exposure. $^{47}$

\section{Conclusion}

This study shows that magnetite iron oxide nanoparticles coated with chitosan and 6-mercaptopurine can be prepared using the ultrasonic irradiation method. The mean size of the superparamagnetic iron oxide nanoparticles and their chitosan-6-mercaptopurine coating was around $9 \mathrm{~nm}$ and 
$19 \mathrm{~nm}$, respectively. The coating process was found to improve the thermal stability of the resulting nanocomposite compared with its uncoated counterpart. Release of the active agent from the nanocomposite was found to occur in a controlled manner via an anion exchange process, indicating that this nanocomposite can be used as a controlled-release formulation. It was also found that the release behavior of the FCMP-D nanocomposite in buffered solutions of $\mathrm{pH} 4.8$ and $\mathrm{pH} 7.4$ was more sustained than for the FCMP nanocomposite. Further, we did not observe any burst release for the active MP in FCMP-D, but did observe this for the FCMP nanocomposite. An in vitro bioassay study showed that the synthesized nanoparticles may serve as an alternative drug delivery system for treatment of cancer, with the added possibility of sparing surrounding normal cells and tissue.

\section{Acknowledgment}

Funding for this research was provided by the Ministry of Higher Education grant of Malaysia (ERGS/1/11/STG/ UPM/01/18, Vot No 5527050).

\section{Disclosure}

The authors report no conflicts of interest in this work.

\section{References}

1. Zhu L, Ma J, Jia N, Zhao Y, Shen H. Chitosan-coated magnetic nanoparticles as carriers of 5-fluorouracil: preparation, characterization and cytotoxicity studies. Colloids Surf B Biointerfaces. 2009;68(1):1-6.

2. Selvaraj V, Alagar M, Hamerton I. Analytical detection and biological assay of antileukemic drug using gold nanoparticles. Electrochim Acta. 2006;52(3):1152-1160.

3. Faridi-Majidi R, Sharifi-Sanjani N, Agend F. Encapsulation of magnetic nanoparticles with polystyrene via emulsifier-free miniemulsion polymerization. Thin Solid Films. 2006;515(1):368-374.

4. Zhao Y, Qiu Z, Huang J. Preparation and analysis of $\mathrm{Fe}_{3} \mathrm{O}_{4}$ magnetic nanoparticles used as targeted-drug carriers. Chinese J Chem Eng. 2008;16(3):451-455.

5. Mudshinge SR, Deore AB, Patil S, Bhalgat CM. Nanoparticles: emerging carriers for drug delivery. Saudi Pharm J. 2011;19(3):129-141.

6. Xu H, Song T, Bao X, Hu L. Site-directed research of magnetic nanoparticles in magnetic drug targeting. J Magn Magn Mater. 2005;293(1):514-519.

7. Zhang J, Lan CQ, Post M, Simard B, Deslandes Y, Hsieh TH. Design of nanoparticles as drug carriers for cancer therapy. Cancer Genomics Proteomics. 2006;3(3-4):147-157.

8. Hejazi R, Amiji M. Chitosan-based gastrointestinal delivery systems. J Control Release. 2003;89(2):151-165.

9. Amidi M, Romeijn SG, Borchard G, Junginger HE, Hennink WE, Jiskoot W. Preparation and characterization of protein-loaded $\mathrm{N}$-trimethyl chitosan nanoparticles as nasal delivery system. J Control Release. 2006;111(1):107-116.

10. Kim JH, Kim YS, Park K, et al. Antitumor efficacy of cisplatin-loaded glycol chitosan nanoparticles in tumor-bearing mice. J Control Release. 2008;127(1):41-49.

11. Sang Yoo H, Eun Lee J, Chung H, Chan Kwon I, Young Jeong S. Selfassembled nanoparticles containing hydrophobically modified glycol chitosan for gene delivery. J Control Release. 2005;103(1):235-243.
12. Mao C, Zhu JJ, Hu YF, et al. Surface modification using photocrosslinkable chitosan for improving hemocompatibility. Colloids Surf B Biointerfaces. 2004;38(1):47-53.

13. Tidd DM, Paterson ARP. A biochemical mechanism for the delayed cytotoxic reaction of 6-mercaptopurine. Cancer Res. 1974;34(4):738-746.

14. Nerstroem VM, Henriksen U, Nielsen PE, Buchardt O, Schmiegelow K, Koch C. Monoclonal antibodies to thioguanine: influence of coupling position on fine specificity. Bioconjug Chem. 1994;5(4):357-363.

15. Sorouraddin MH, Khani MY, Amini K, Naseri A, Asgari D, Rashidi MR. Simultaneous determination of 6-mercaptopurine and its oxidative metabolites in synthetic solutions and human plasma using spectrophotometric multivariate calibration methods. Bioimpacts. 2011;1(1):53-62.

16. Acevedo-Chávez R, Costas ME, Escudero R. Magnetic study of the novel polynuclear compound [Cu (II)(6-mercaptopurinolate $\left.\left.{ }^{2-}\right)\right]_{\mathrm{n}}$. J Solid State Chem. 1997;132(1):78-87.

17. Bariyanga J, Luyt AS. Synthesis, Fourier transform infrared, nuclear magnetic resonance and thermal analysis of sodium and platinum complexes of 6-mercaptopurine. J Mol Struct. 2001;559(1): 49-54.

18. Lee HS, Shao H, Huang Y, Kwak BK. Synthesis of MRI contrast agent by coating superparamagnetic iron oxide with chitosan. IEEE Trans Magn. 2005;41(10):4102-4104.

19. Genta I, Perugini P, Pavanetto F. Different molecular weight chitosan microspheres: influence on drug loading and drug release. Drug Dev Ind Pharm. 1998;24(8):779-784.

20. Sinha VR, Singla AK, Wadhawan S, et al. Chitosan microspheres as a potential carrier for drugs. Int J Pharm. 2004;274(1):1-33.

21. Ghotbi MY, bin Hussein MZ. Controlled release study of an anticarcinogenic agent, gallate from the surface of magnetite nanoparticles. J Phys Chem Solids. 2012;73:936-942.

22. Hassanjani-Roshan A, Vaezi MR, Shokuhfar A, Rajabali Z. Synthesis of iron oxide nanoparticles via sonochemical method and their characterization. Particuology. 2011;9(1):95-99.

23. Su C-C, Yang J-S, Lin S-Y, et al. Curcumin inhibits WEHI-3 leukemia cells in BALB/c mice in vivo. In Vivo. 2008;22(1):63-68.

24. Dorniani D, Hussein MZB, Kura AU, Fakurazi S, Shaari AH, Ahmad Z. Preparation of $\mathrm{Fe}_{3} \mathrm{O}_{4}$ magnetic nanoparticles coated with gallic acid for drug delivery. Int J Nanomedicine. 2012;7:5745-5756.

25. Xia SJ, Ni ZM, Xu Q, Hu BX, Hu J. Layered double hydroxides as supports for intercalation and sustained release of antihypertensive drugs. J Solid State Chem. 2008;181(10):2610-2619.

26. Ribeiro C, Arizaga GGC, Wypych F, Sierakowski MR. Nanocomposites coated with xyloglucan for drug delivery: in vitro studies. Int J Pharm. 2009;367(1):204-210.

27. Zhang H, Zou K, Guo S, Duan X. Nanostructural drug-inorganic clay composites: structure, thermal property and in vitro release of captoprilintercalated Mg-Al-layered double hydroxides. J Solid State Chem. 2006;179(6):1792-1801.

28. Zhang B, Wang DF, Li HY, Xu Y, Zhang L. Preparation and properties of chitosan-soybean trypsin inhibitor blend film with anti-Aspergillus flavus activity. Ind Crop Prod. 2009;29(2):541-548.

29. Costa-Júnior ES, Barbosa-Stancioli EF, Mansur AAP, Vasconcelos WL, Mansur HS. Preparation and characterization of chitosan/poly (vinyl alcohol) chemically crosslinked blends for biomedical applications. Carbohydr Polym. 2009;76(3):472-481.

30. Fan M, Hu Q, Shen K. Preparation and structure of chitosan soluble in wide $\mathrm{pH}$ range. Carbohydr Polym. 2009;78(1):66-71.

31. Nidhin M, Indumathy R, Sreeram KJ, Nair BU. Synthesis of iron oxide nanoparticles of narrow size distribution on polysaccharide templates. Bull Mater Sci. 2008;31(1):93-96.

32. Ma H, Qi X, Maitani Y, Nagai T. Preparation and characterization of superparamagnetic iron oxide nanoparticles stabilized by alginate. Int J Pharm. 2007;333(1):177-186.

33. Chaparadza A, Rananavare SB, Shutthanandan V. Synthesis and characterization of lithium-doped tin dioxide nanocrystalline powders. Mater Chem Phys. 2007;102(2):176-180. 
34. Yasin Y, Ismail NM, Hussein MZ, Aminudin N. Synthesis and characterization of lawsone-intercalated $\mathrm{ZnAl}$ layered double hydroxides. $J$ Biomed Nanotechnol. 2011;7(3):486-488.

35. Bajaj B, Malhotra BD, Choi S. Preparation and characterization of bio-functionalized iron oxide nanoparticles for biomedical application. Thin Solid Films. 2010;519(3):1219-1223.

36. Ge Y, Zhang Y, Xia J, et al. Effect of surface charge and agglomerate degree of magnetic iron oxide nanoparticles on KB cellular uptake in vitro. Colloids Surf B Biointerfaces. 2009;73(2):294-301.

37. Qu JB, Shao H, Jing GL, Huang F. PEG-chitosan-coated iron oxide nanoparticles with high saturated magnetization as carriers of 10-hydroxycamptothecin: preparation, characterization and cytotoxicity studies. Colloids Surf B Biointerfaces. 2013;102: 37-44.

38. Ambrogi V, Fardella G, Grandolini G, Perioli L, Tiralti MC. Intercalation compounds of hydrotalcite-like anionic clays with anti-inflammatory agents, II: uptake of diclofenac for a controlled release formulation. AAPS PharmSciTech. 2002;3(3):77-82.

39. Al Ali SHH, Al-Qubaisi M, Hussein MZ, Ismail M, Zainal Z, Hakim MN. Comparative study of $\mathrm{Mg} / \mathrm{Al}$-and $\mathrm{Zn}$ /Al-layered double hydroxideperindopril erbumine nanocomposites for inhibition of angiotensinconverting enzyme. Int J Nanomedicine. 2002;7:4251-4262.

40. Zhang H, Zou K, Sun H, Duan X. A magnetic organic-inorganic composite: synthesis and characterization of magnetic 5-aminosalicylic acid intercalated layered double hydroxides. J Solid State Chem. 2005;178(11):3485-3493
41. Khan AI, O'Hare D. Intercalation chemistry of layered double hydroxides: recent developments and applications. J Mater Chem. 2002;12(11): 3191-3198.

42. Hussein-Al-Ali SH, Al-Qubaisi M, Hussein MZ, Ismail M, Zainal Z, Hakim MN. In vitro inhibition of histamine release behavior of cetirizine intercalated into $\mathrm{zn} / \mathrm{al}$-and $\mathrm{mg} / \mathrm{al}$-layered double hydroxides. Int $\mathrm{J} \mathrm{Mol}$ Sci. 2002;13(5):5899-5916.

43. Dong L, Yan L, Hou WG, Liu SJ. Synthesis and release behavior of composites of camptothecin and layered double hydroxide. J Solid State Chem. 2010;183(8):1811-1816.

44. Ho YS, Ofomaja AE. Pseudo-second-order model for lead ion sorption from aqueous solutions onto palm kernel fiber. J Hazard Mater. 2006;129(1):137-142.

45. Cuin A, Massabni AC, Pereira GA, et al. 6-Mercaptopurine complexes with silver and gold ions: anti-tuberculosis and anti-cancer activities. Biomed Pharmacother. 2011;65(5):334-338.

46. Serpe L, Catalano MG, Cavalli R, et al. Cytotoxicity of anticancer drugs incorporated in solid lipid nanoparticles on HT-29 colorectal cancer cell line. Eur J Pharm Biopharm. 2004;58(3):673-680.

47. Ankamwar B, Lai TC, Huang JH, et al. Biocompatibility of $\mathrm{Fe}_{3} \mathrm{O}_{4}$ nanoparticles evaluated by in vitro cytotoxicity assays using normal, glia and breast cancer cells. Nanotechnology. 2010;21(7):075102.
Drug Design, Development and Therapy

\section{Publish your work in this journal}

Drug Design, Development and Therapy is an international, peerreviewed open-access journal that spans the spectrum of drug design and development through to clinical applications. Clinical outcomes, patient safety, and programs for the development and effective, safe, and sustained use of medicines are a feature of the journal, which

\section{Dovepress}

has also been accepted for indexing on PubMed Central. The manuscript management system is completely online and includes a very quick and fair peer-review system, which is all easy to use. Visit http://www.dovepress.com/testimonials.php to read real quotes from published authors.

Submit your manuscript here: http://www.dovepress.com/drug-design-development-and-therapy-journal 